\title{
A DECISÃO DO SUPREMO TRIBUNAL FEDERAL SOBRE PARENTALIDADES SIMULTÂNEAS E A ADOÇÃO LEGAL: uma brecha para mudanças ou uma afronta ao princípio da isonomia?
}

Dóris Ghilardi

\section{RESUMO:}

A teoria da multiparentalidade, aceita recentemente pelo Supremo Tribunal Federal (STF), que admitiu a simultaneidade de filiações com repercussão geral, abre o debate para diversos impasses jurídicos. Entre eles, uma intrigante questão relacionada aos casos de adoção legal, haja vista que, se a decisão que acolheu a dupla parentalidade possibilitou o reconhecimento do vínculo paterno biológico de modo concomitante ao socioafetivo, e se, a lei de adoção prevê expressamente que o filho adotivo será desligado dos seus vínculos biológicos, aparentemente tem-se um descompasso no tratamento dos casos oriundos da adoção à brasileira em relação à adoção regular. Ora, se a decisão da Corte Suprema socorre os filhos que possuem vínculos parentais socioafetivos constituídos de outros modos que não a adoção formal a estabelecerem a multiparentalidade, diante do óbice previsto na lei de adoção, como será a questão tratada? Com base em observações doutrinárias e julgados a proposta tem por objeto a reflexão crítica sobre o tema.

PALAVRAS-CHAVE: Direito de Família; Filiação; Multiparentalidade; Adoção Legal; Princípio da Isonomia;

\section{THE DECISION OF THE SUPREME FEDERAL COURT ON SIMULTANEOUS PARENTALITIES AND LEGAL ADOPTION: a breach for change or an affront to the principle of isonomy?}

\begin{abstract}
:
The theory of multiparentality, recently accepted by the Federal Supreme Court (STF), which admitted the simultaneity of affiliations with general repercussions, opens the debate for several legal impasses. Among them, an intriguing question related to cases of legal adoption, given that if the decision that embraced dual parenting made it possible to recognize the biological paternal bond in a concomitant way to the socioaffective and if the adoption law expressly provides that the adopted child will be turned off their biological links, there seems to be a mismatch in the treatment of cases coming from the Brazilian adoption in relation to regular adoption. If the decision of the Supreme Court relieves children who have socioaffective parenting ties other than formal adoption to establish multiparentality, given
\end{abstract}


the obstacle foreseen in the adoption law, how will the question be treated? Based on doctrinal and judged observations, according to the deductive method, the proposal aims to reflect on the subject, since, in principle, there seems to be an incongruity, especially regarding the principle of isonomy, which prohibits treatment other than membership.

KEYWORD: Family right; Affiliation; Multiparentality; Legal Adoption; Principle of Isonomy;

\section{INTRODUÇÃO}

A dinâmica das relações familiares tem experimentado mudanças cruciais nos últimos tempos, desafiando o judiciário por meio de demandas inovadoras e que envolvem questões complexas, entre elas, as relações paterno-filiais. Se no passado a família atribuía papéis definidos a todos os integrantes, hoje o parentesco atravessa um período de desolidificação e reconstrução de suas categorias.

As uniões marcadas pela fluidez contribuem para o surgimento de entidades reconstituídas - as chamadas famílias mosaicos - dando espaço para o convívio entre pessoas ligadas tanto por laços afetivos, quanto biológicos.

Em um passado não muito remoto, a filiação era decorrente de vínculo biológico, civil - caso da adoção - ou então da chamada paternidade jurídica ou presumida, que considerava o homem casado como pai da criança.

As discriminações eram visíveis e giravam em torno da concentração do patrimônio no seio da família casamentária. Nem aos filhos "bastardos", nem aos adotivos eram reconhecidos direitos iguais, pelo contrário, o direito de herança integral era restrito aos filhos biológicos.

Com a constitucionalização do Direito de Família, o filho, independentemente de sua origem, passou a ser tratado como igual, pouco importando a sua origem. A nova tábua 
axiológica repaginou as relações familiares, que passaram a se reestruturar com base na solidariedade, na igualdade, na paternidade responsável, na convivência familiar, entre tantos outros princípios.

Todas essas mudanças fizeram emergir uma novo tipo de filiação, cunhada como filiação socioafetiva, responsável por estremecer os alicerces da genética e dos padrões de parentesco estabelecidos legalmente.

Contudo, mesmo com o reconhecimento das diversas formas possíveis de parentalidade - civil, biológica e socioafetiva - no passado, não se tinham dúvidas de que eram excludentes para fins legais, porém, na última década, começaram a surgir decisões aceitando a sua concomitância e, em recente julgado do STF, esse cenário mudou para reconhecer expressamente a simultaneidade de vínculos parentais.

A multiparentalidade, também já há algum tempo aventada doutrinariamente, desafiava diversas polêmicas, como a questão do registro civil, dos alimentos e do direito sucessório. A decisão do STF, de efeitos vinculantes, consagrou não só a possibilidade da coexistência de vínculos paterno-filiais biológico e socioafetivo, como reconheceu todas as consequências jurídicas daí advindas.

Em que pese a importância e a nítida alteração de paradigma estabelecido pela decisão, o tema suscitará ainda diversas reflexões, algumas delas enfrentadas neste artigo. Porém, o questionamento central que se propõe, diz respeito ao confronto que se estabelece entre a decisão do Supremo e o Estatuto da Criança e do Adolescente, posto que se a multiparentalidade significa a permissibilidade de mais de um vínculo paterno-filial ao mesmo tempo, a estruturação da adoção regular determina a alteração do registro civil da criança, para que sejam desfeitos os laços com a família biológica.

Diante deste aparente conflito, pretende-se, com apoio da análise de decisões judiciais sobre o tema, verificar se a questão específica já foi enfrentada, bem como, se há 
elementos que sugerem um descompasso no tratamento da filiação oriunda da adoção à brasileira, em relação à adoção regularmente efetuada.

Mais do que encontrar respostas, o objetivo é refletir sobre os rumos da aplicabilidade da multiparentalidade no Brasil, tema recente e com vários desafios, que justificam a sua abordagem, até porque, o seu reconhecimento vai de encontro com o movimento do direito alienígena, bem mais conservador.

Para tanto, com base no método dedutivo e dialético, abordar-se-á o tema, apoiado em pesquisas doutrinárias e jurisprudenciais. A estruturação compreenderá o diálogo entre a concomitância de vínculos parentais e a recente decisão do STF sobre o tema, contemplando, em seguida, as diretrizes sobre a adoção à brasileira e a adoção legal, buscando verificar um possível descompasso do tema da multiparentalidade em relação às duas situações. Por fim, com base em decisões judiciais, descobrir a possível tendência para a problemática aqui levantada.

\section{PARENTALIDADES SIMULTÂNEAS E A DECISÃO DO STF}

O sistema jurídico precisa acompanhar as transformações ocorridas na sociedade. A família historicamente tem experimentado inúmeras mutações que requerem soluções nem sempre fáceis. A quebra de paradigmas há séculos instalado, faz emergir novos valores, novas configurações e arranjos.

Nas palavras de Zigmunt Bauman (2004, p. 112):

uma inédita fluidez, fragilidade e transitoriedade em construção (a famosa "flexibilidade") marcam todas as espécies de vínculos sociais que, um década atrás, combinaram-se para construir um arcabouço duradouro e 
fidedigno dentro do qual se pôde tecer com segurança uma rede de interações humanas.

Rede segura que não mais se sustenta, lugares outrora preestabelecidos, que nada mais são "do que lugares estruturantes simbólicos” passíveis de serem reconfigurados. (PEREIRA, 2012, p. 152).

Tanto é assim que a estrutura monogâmica e casamentária agora divide espaço com as relações paralelas, as famílias informais ou outras configurações; já as figuras paterna e materna, ocupadas no passado, pelo marido e mulher, são agora exercidas não raras vezes, pelas figuras de dois pais e/ou duas mães, no caso das famílias homoafetivas.

Se há bem pouco tempo a discussão sobre os vínculos paterno-filiais giravam em torno do estabelecimento da hierarquia entre filiação biológica e afetiva, o tema recentemente e de modo inovador, consagrou a concomitância dos vínculos, acolhendo a tese da multiparentalidade.

O STF, em fins de setembro de 2016, na Repercussão Geral $622^{1}$ que analisaria a prevalência da socioafetividade em detrimento da paternidade biológica, culminou por reconhecer a paternidade socioafetiva em coexistência com a paternidade biológica, em igualdade de condições, com todas as suas consequências patrimoniais e extrapatrimoniais. Extrai-se do voto:

(....) Os arranjos familiares alheios à regulação estatal, por omissão, não podem restar ao desabrigo da proteção a situações de pluriparentalidade, por isso que merecem tutela jurídica concomitante, para todos os fins de direito, os vínculos parentais de origem afetiva e biológica, a fim de prover a mais completa e adequada tutela aos sujeitos envolvidos, ante os princípios constitucionais da dignidade da pessoa humana (art. 1, III) e da paternidade responsável (art. 226, par. 7). 16. Recurso Extraordinário a que se nega provimento, fixando-se a seguinte tese jurídica para aplicação a casos semelhantes: "A

\footnotetext{
${ }^{1}$ Recurso substituído pelo 898.060, sem alteração de conteúdo.
} 
paternidade socioafetiva, declarada ou não em registro público, não impede o reconhecimento do vínculo de filiação concomitante baseado na origem biológica, com todas as suas consequências patrimoniais e extrapatrimoniais. (STF, Rex 898.060, Rel Min Luiz Fux, Pleno, j. 21/09/2016)

A decisão do STF levou em consideração a situação fática existente, viabilizando o vínculo jurídico concomitante entre as paternidades biológica e socioafetiva não só do caso concreto, mas também fixando tese no sentido de ampliação do entendimento para situações semelhantes.

A solução engendrada mudou o paradigma até então existente, responsável por definir um critério para os casos em que havia conflitos de vínculos parentais. Chegou-se a estabelecer hierarquia entre eles, dividindo-se os posicionamentos sobre qual laço deveria prevalecer, se o biológico ou o afetivo.

Entre muitas discussões travadas acerca do tema, chegou-se ao absurdo de se reconhecer judicialmente a possibilidade de duplo registro de paternidade, ou até mesmo a paternidade para fins específicos - guarda e seguro DPVAT, por exemplo -, porém sem quaisquer outros efeitos, criando nítidas distinções de filiação. Em outras palavras, reconhecia-se um direito pela metade, o que era inaceitável.

Várias vozes na doutrina, já se manifestavam favoravelmente à teoria da multiparentalidade, entre elas Maria Berenice Dias (2013, p. 385) que destacava que para "o reconhecimento da filiação pluriparental, basta flagrar o estabelecimento do vínculo de filiação com mais de duas pessoas."

Ou em estudo mais aprofundado, Pedro Belmiro Welter (2009, p. 233) destacava a possibilidade do reconhecimento da multiparentalidade, salientando que a nova compreensão da família requer do julgador uma nova percepção, que faz com que estranhe o que lhe era familiar (mundo biológico apenas) e, "ao mesmo tempo, o convoca a tornar conhecido o que 
lhe surge como estranho (os mundos afetivos e ontológico), somando-se todos os direitos decorrentes dessa condição humana tridimensional."

Tornado regra agora, Cristiano Chaves de Farias e Nelson Roselvald (2017, p. 619) registram que a pluriparentalidade não pode ser desvirtuada, chamando a atenção de que se trata de instituto "de caráter completamente excepcional, permitindo em casos específicos e episódicos (nos quais há comprovação da concomitâncias dos vínculos filiais) uma simultaneidade de pais/e ou mães”.

A preocupação é relevante até para que não seja utilizada de subterfúgio para fins meramente econômicos, inspirando demandadas que visem unicamente o patrimônio, sem qualquer aproximação ou afeto estabelecido entre pai e filho.

Estabelecer critérios hierárquicos nos conflitos advindos das relações paterno ou materno filiais, como chegaram a sugerir alguns autores, o que se repetia nos julgados, não parecia ser o mais adequado. A tese de multiparentalidade, aplicada aos casos específicos, em que o laço filiatório duplo realmente se faz presente no mundo fático, não deixa de ser o reconhecimento jurídico do que ocorre na vida real (GHILARDI, 2013, p. 78)².

Se é certo que o vínculo meramente biológico não mais é considerado condizente com os ideais da dignidade da pessoa humana, da solidariedade e da afetividade, podendo ser, inclusive, decorrente de um ato não planejado ou até mesmo oriundo de crime, por outro lado, também é certo de que a lei prevê uma série de obrigações que decorrem da paternidade ou da

\footnotetext{
2 "Quando um indivíduo assume, consciente e espontaneamente a paternidade, criando laços de afeto com o filho, não se entende correto, por nenhuma razão, excluir esse vínculo posteriormente. Porém, retirar as obrigações legais daquele que gerou um filho, mesmo que por um ato não desejado, é o mesmo que premiá-lo, em razão de terceira pessoa ter assumido o seu papel. Isso tudo sem falar do filho, negar-lhe uma das paternidades é impingir-lhe uma penalidade em decorrência de uma situação por ele não provocada." (Ghilardi, 2013, p. 78)
} 
maternidade. Por sua vez, a filiação socioafetiva tem a vantagem de ser uma relação construída, desejada, espontânea. Mas será que isso é suficiente para excluir a biológica?

Indagações como estas pareciam adequadas e, de fato, levaram o STF a admitir o tema da filiação, como repercussão geral, a tratar sobre uma provável prevalência de uma paternidade sobre a outra. Contudo, o Ministro relator Luiz Fux, entendeu que essa alternativa não parecia apropriada, além de poder causar um retrocesso ao direito de família brasileiro. Destacou em seu acórdão, de forma exemplificativa: "Caso o STF decidisse pela prevalência do vínculo biológico sobre o afetivo, colocaríamos em risco a importante categoria da sociafetividade, que foi edificada no Brasil durante as últimas três décadas.” (STF, 2017) ${ }^{3}$

Nesse diapasão, a multiparentalidade surge como um fenômeno típico da contemporaneidade, construída com base em valores plurais, que exigem o reconhecimento de todas as formas de afeto possíveis e não mais apenas aquelas emolduradas no passado.

Contudo, a partir de agora, os contornos a serem dados ao tema demandarão muita cautela, que exigirá resolução de inúmeras questões relacionadas aos efeitos da multiparentalidade.

\section{A MULTIPARENTALIDADE ENTRE A ADOÇÃO À BRASILEIRA E A ADOÇÃO LEGAL: UM APARENTE DESCOMPASSO}

O Estatuto da Criança e do Adolescente estabelece no artigo 41 que "a adoção atribui a condição de filho ao adotado, com os mesmos direitos e deveres, inclusive sucessórios, desligando-o de qualquer vínculo com pais e parentes, salvo os impedimentos matrimoniais."

\footnotetext{
${ }^{3}$ STF, RE n. 898.060
} 
Nem a morte restabelecerá o poder familiar dos pais biológicos, segundo previsão legal. Para garantir o desligamento de vínculos, o registro civil original é cancelado, passando a criança a ter um novo registro, com os dados dos pais e avós atuais, sem qualquer anotação sobre a adoção.

Com efeito, a regulamentação do ECA, deixa clara a impossibilidade de multiparentalidade nos casos de adoção regular. A única permissibilidade legal diz respeito ao acesso irrestrito ao processo de adoção, bem como o direito ao reconhecimento da origem genética, sem extensão de qualquer outro efeito.

Se até bem pouco tempo, a construção jurídica da adoção estava em conformidade com o restante das disposições legais, inclusive com a Constituição da República Federativa do Brasil de 1988, que igualou todos os filhos e proibiu designações discriminatórias ${ }^{4}$, a recente decisão do STF parece ter criado um impasse a ser solucionado em breve, no tocante a aplicação da multiparentalidade.

Não é incomum no Direito brasileiro, quiçá no Direito de Família a derrogabilidade das regras legais por precedentes jurídicos, exemplo disso é a questão das uniões homoafetivas. O tema da multiparentalidade já há algum tempo vinha desafiando o Poder Judiciário com demandas envolvendo conflitos de vínculos parentais e, junto com elas, variados problemas decorrentes de seu reconhecimento.

Questionava-se se ela seria um direito somente do filho, ou se também dos pais; se deveria ou não existir hierarquia entre a filiação biológica e a socioafetiva, se positiva a resposta, qual delas deveria prevalecer; se reconhecida a duplicidade de vínculos, como seria efetuado o registro; se permitido o registro, como ficaria a questão dos alimentos e da herança; se seria possível a sua duplicidade ou não, e assim por diante.

\footnotetext{
${ }^{4}$ Art. 227, par. 6 "os filhos, havidos ou não da relação do casamento, ou por adoção, terão os mesmos direitos e qualificações, proibidas quaisquer designações discriminatórias relativas à filiação."
} 
As dúvidas também atingem outras áreas, como o Direito Administrativo, na questão do nepotismo; o Eleitoral, com a inelegibilidade; o Previdenciário, em relação aos direitos dessa natureza.

Tantas indagações são normais até em razão da ruptura de um modelo há séculos estabelecido, com soluções unitárias e pré-estabelecidas. Contudo, a elasticidade da vida e dos relacionamentos, distancia-se cada vez mais do molde engessado das facetas parentais, ocasionando conflitos que requerem soluções condizentes com a pluralidade de modos de vida atual.

Porém, nesse emaranhado de incertezas, com a valorização do afeto tornando-se um importante vetor no direito de família brasileiro, institutos sólidos passaram por revisão, caso da adoção à brasileira, que passou da recriminação à valorização.

Uma criança que fosse registrada apenas pela mãe, por exemplo, caso o atual companheiro quisesse registrá-lo como filho, teria que ingressar com pedido judicial de adoção unilateral.

Recentemente, várias corregedorias de justiça estaduais editaram resoluções permitindo o registro socioafetivo diretamente em Cartório, sem a necessidade de decisão judicial, caso do Amazonas, Ceará, Pernambuco e Santa Catarina.

Com objetivo de regularizar e padronizar o procedimento extrajudicial em todo Brasil, já que ainda não há regramento legal, atendendo ao pedido de providências formulado pelo Instituto Brasileiro de Direito de Família, em março do corrente ano, o Ministro do Superior Tribunal de Justiça e também Corregedor-Geral, João Otávio Noronha, solicitou a regulamentação do registro extrajudicial da parentalidade socioafetiva, junto aos Cartórios de Registro Civil ${ }^{5}$.

${ }^{5}$ pedido de providências n. 0002653-77.2015.2.00.0000, em curso perante o Conselho Nacional de Justiça. 
Contudo, quando já existente vínculo registral, qualquer realidade distinta, cujo sujeito pretendesse mudar esse liame, enfrentava longas batalhas judiciais, sem garantia de conseguir a alteração registral.

Tantas inquietações e desejos de correção de um vínculo registral muitas vezes não condizente com a realidade, não pouparam o Judiciário, que tem sido provocado constantemente a enfrentar e solucionar conflitos parentais, culminando em decisões por vezes inesperadas, ora privilegiando a biologia, ora o afeto.

Eis que surge a teoria da multiparentalidade e aos poucos a permissibilidade de, em algumas situações, não se privilegiar nenhum laço, mas sim somá-los.

No início, questões aparentemente mais simples, como por exemplo um filho que tivesse perdido o pai biológico e passasse a ser criado por um pai socioafetivo conseguia, no máximo, por meio de decisão judicial, acrescentar o sobrenome do padrasto no seu registro. Nesse sentido, inclusive, adveio a Lei n. 11.924/2009, que regulamentou a possibilidade de o enteado ou enteada adotar o patronímico da família do padrasto ou da madrasta.

Já em 2012, decisão do Tribunal de Justiça de São Paulo foi além, e permitiu a inclusão da madrasta na certidão de nascimento de um rapaz, revertendo a sentença de primeira instância, que reconheceu a situação, mas argumentou não haver espaço na lei para a inscrição de duas mães ${ }^{6}$.

6 TJSP, AC n. 0006422-26.2011.8.26.0286, 1 Câmara Direito Privado, julgado em 14/08/12. Ementa: "MATERNIDADE SOCIOAFETIVA. Preservação da Maternidade Biológica Respeito à memória da mãe biológica, falecida em decorrência do parto, e de sua família - Enteado criado como filho desde dois anos de idade Filiação socioafetiva que tem amparo no art. 1.593 do Código Civil e decorre da posse do estado de filho, fruto de longa e estável convivência, aliado ao afeto e considerações mútuos, e sua manifestação pública, de forma a não deixar dúvida, a quem não conhece, de que se trata de parentes - A formação da família moderna não-consanguínea tem sua base na afetividade e nos princípios da dignidade da pessoa humana e da solidariedade Recurso provido. 
De forma totalmente surpreendente, ainda em 2012, uma sentença da Comarca de Ariquemes, em Rondônia, reconheceu a possibilidade registral de dois pais na certidão de uma criança. No caso em concreto, a menina foi registrada pelo companheiro de sua mãe à época de seu nascimento, caso nítido de adoção à brasileira. Mais tarde, a criança descobriu a sua origem biológica e, devidamente representada por sua mãe, ingressou com demanda pretendendo a alteração do registro civil. O parecer, da Promotora de Justiça, foi no sentido de reconhecimento da simultaneidade de vínculos paternos, o que foi acolhido pela Juíza, entendendo que a ligação afetiva da menina se dava em relação a ambos os pais, não havendo razão para cortar nenhuma das relações ${ }^{7}$.

A partir daí, começaram a surgir em todo o Brasil decisões reconhecendo a multiparentalidade registral, muitas delas baseada nessa decisão citada.

\subsection{A Decisão do Supremo Tribunal: novos rumos}

A decisão do STF, conforme já demostrado acima, não só reconheceu a possibilidade da coexistência de vínculo paterno-filial, com a extensão de todos os efeitos, como teve recomendação de aplicação para casos semelhantes.

Pois bem. Então, segundo entendimento do STF, toda vez que um filho for registrado por um pai socioafetivo, isso não impede a concomitância de vínculo com o pai biológico. Também quando um filho tiver como pai registral o pai biológico e, posteriormente, estabelecer vínculos com o pai socioafetivo. Neste sentido, é a decisão recente e posterior a

\footnotetext{
${ }^{7}$ Notícia extraída do sítio jus.com.br, acesso em 07/04/2017;
} 
do STF, do Tribunal de Justiça do Distrito Federal que possibilitou a inclusão do pai socioafetivo, mesmo existindo registro do pai biológico ${ }^{8}$.

Atento ao rumo dado pelo STF, a Terceira Turma, do Superior Tribunal de Justiça, reformando decisão do tribunal gaúcho, garantiu a um sexagenário, em ação de reconhecimento recente, o direito de receber herança do pai biológico, mesmo já tendo sido beneficiário do patrimônio deixado pelo pai socioafetivo. O colegiado entendeu que, sendo um sujeito criado por um pai socioafetivo, que consagra tal relação em seu registro de nascimento, ao descobrir sobre sua origem biológica, passa a ter direito a reconhecer sua ancestralidade, bem como a todos os efeitos patrimoniais decorrentes do vínculo genético.

No caso concreto, o autor teria tomado conhecimento da suposta filiação biológica em 1981, porém, somente em 2008 ingressou com a demanda. O pai biológico faleceu antes mesmo de ser citado. Os sucessores, incluídos no polo passivo, alegaram que o Autor moveu a ação com vistas unicamente ao recebimento da herança. Contudo, o argumento não foi acolhido. Segundo a Ministra Nancy Andrighi “pode-se especular o porquê da demora do autor na busca pelo reconhecimento da paternidade biológica, mas não se pode negar os efeitos dela, uma vez comprovada" $"$.

${ }^{8}$ DIREITO DE FAMÍLIA E CONSTITUCIONAL. AÇÃO DE ADOÇÃO. MULTIPARENTALIDADE. RECONHECIMENTO DO VÍNCULO BIOLÓGICO PREEXISTENTE. PATERNIDADE SOCIOAFETIVA. DUPLA PARENTALIDADE. POSSIBILIDADE. DECISÃO DO STF COM REPERCUSSÃO GERAL. 1. A paternidade biológica declarada em registro público não impede o reconhecimento do vínculo de filiação concomitante baseado na origem socioafetiva, com os efeitos jurídicos próprios, como desdobramento do princípio da dignidade humana, na sua dimensão de tutela da felicidade e realização pessoal dos indivíduos a partir de suas próprias configurações existenciais. 2. "A omissão do legislador brasileiro quanto ao reconhecimento dos mais diversos arranjos familiares não pode servir de escusa para a negativa de proteção a situações de pluriparentalidade." Tese fixada com repercussão geral no julgamento do RE 898060/SC - STF. 3. Recurso conhecido e provido. (TJDF, rel. Des. Getúlio de Moraes Oliveira, 05/04/2017)

${ }^{9}$ Dados extraídos da página oficial do STJ, www.stj.jus.br, com o tema "filiação socioafetiva não impede reconhecimento de paternidade biológica e seus efeitos patrimoniais", acesso em 07/04/2017; 
A construção da tese fixada pelo STF, não exige que o filho tenha convivência com o pai biológico, para que seja possível a duplicidade registral, basta então saber quem é o pai biológico, sem necessidade de estabelecimento de contato. Nessa senda, seguiu o acórdão do STJ, do qual se extrai do voto do relator que a paternidade gera responsabilidades morais e patrimoniais, podendo ser citado que "a pessoa criada e registrada por pai socioafetivo não precisa, portanto, negar sua paternidade biológica, e muito menos abdicar de direitos inerentes ao seu novo status familiae, tais como os direitos hereditários" ${ }^{\prime 1}$.

Os julgados encontrados antes da decisão do STF, em geral, reconheciam a possibilidade de multiparentalidade, quando a alteração registral pretendia acrescer a paternidade ou maternidade socioafetiva. Já quando o registro era para inclusão de vínculo biológico, poucas decisões autorizavam a simultaneidade.

O paradigma estabelecido pela decisão do STF diz respeito expressamente a esta segunda situação, sem, contudo, exigir a convivência. Na doutrina, encontram-se vozes distoantes acerca desse entendimento, caso de Cristiano Chaves de Farias e Nelson Rosenvald (2017, p. 619), para quem a multiparentalidade tem o "propósito de garantir a isonomia filiatória, e não para permitir a livre escolha de pais, movidos por vantagens econômicas”.

Ou seja, a multiparentalidade somente deveria ser reconhecida nos casos em que realmente exista a relação múltipla entre pais e filhos. Diante disso, se é certo que o mundo dos fatos admite a convivência plural, certo também é, que cada caso prático dependerá de interpretação e sensibilidade por parte dos julgadores, para que possam distinguir a linha

\footnotetext{
${ }^{10}$ Dados extraídos da página oficial do STJ, www.stj.jus.br, com o tema "filiação socioafetiva não impede reconhecimento de paternidade biológica e seus efeitos patrimoniais", acesso em 07/04/2017;
} 
tênue que separa as razões afetivas das razões patrimoniais, para que em nome do afeto, não se priorize questões de ordem estritamente financeiras ${ }^{11}$.

\subsection{ADOÇÃO À BRASILEIRA VERSUS ADOÇÃO LEGAL}

Com o objetivo de enfrentar o tema central do artigo e considerando a premissa estabelecida pelo STF, a questão que se coloca é: o laço biológico poderá ser reconhecido em concomitância com o socioafetivo, mesmo que este decorra de processo de adoção reconhecido por decisão judicial, a mesma que anteriormente rompeu estes laços?

Em princípio, parece que apenas os casos em que a paternidade socioafetiva se constituiu sem um processo de adoção regular, isso seria plausível. Esse é o entendimento de Rolf Madaleno (2016, p. 13), que chama a atenção para o conflito que causa a decisão do STF. O autor gaúcho, inclusive, posiciona-se contrariamente à tese de multiparentalidade, entendendo que não há necessidade de alteração registral, basta o mero reconhecimento.

A proibição de simultaneidade de vínculos no caso da adoção regular é expressa. Deste modo, caberia a aplicação somente nos casos da chamada adoção à brasileira, em que uma pessoa registra filho biológico de outrem como sendo seu.

O impasse está posto, visto que se assim se entender, em duas situações semelhantes, em que um filho é registrado por um pai/mãe socioafetivo e, mais adiante, passar a também conviver com o biológico, duas situações distintas surgem, ferindo o princípio da isonomia de filiação.

O filho que foi apenas registrado pelo pai/mãe socioafetivo, poderá requerer a inclusão da paternidade/maternidade biológica, com todos os seus efeitos. Já se foi regularmente adotado, desligado de sua família biológica, com todos os laços jurídicos

11 O parecer do Ministério Público Federal, no caso em destaque, também releva a preocupação com demandas abusivas, porém, conclui que "eventuais abusos podem e devem ser controlados no caso concreto". 
cortados, mesmo se conviver com o pai ou mãe biológica, não terá direito a reincluí-la na certidão.

A fim de verificar em que sentido caminham as decisões já proferidas, passa-se a citar alguns julgados.

Antes mesmo da decisão do STF, em 2013, no Recife, o Juiz da 2a Vara da Infância e Juventude de Pernambuco, em caso de adoção unilateral, já havia em sua sentença autorizado que, na certidão de nascimento da criança constasse, além do nome do pai e da mãe biológica, também o nome da madrasta, entendendo que a afetividade é o mais importante elo da família. No caso concreto, a mãe biológica havia aberto mão da criança quando de seu nascimento, em razão de sua parca situação financeira, passando a guarda, provisoriamente, para a atual companheira do pai da criança. Apesar disso, a genitora manteve contato com o filho e não queria que seu nome fosse suprimido da certidão do menino ${ }^{12}$.

Em Minas Gerais, na Comarca de Nova Lima, em 2014, em pedido de adoção, feito por um casal, com o qual a criança se encontrava desde o nascimento, em razão do falecimento da genitora dias após o parto, foi reconhecida a possibilidade de acrescentar o nome dos pais adotivos, na certidão da criança, sem o rompimento dos laços biológicos. Foi considerado tanto pelo Promotor de Justiça, quanto pelo Juiz que, diante do fato da mãe não ter abandonado a criança, não caberia a destituição do poder familiar privilegiando, assim, o melhor interesse da criança ${ }^{13}$.

Na $3^{\text {a }}$ Vara da Infância e Juventude de Fortaleza, em 2015, em caso semelhante ao mineiro, a Juíza titular, declarou a adoção de uma menina, pelo casal que a estava criando

\footnotetext{
${ }^{12}$ Notícia extraída da página do Conjur, sítio www.conjur.com.br, acesso em 08/04/2017;

${ }^{13}$ Notícia retirada do sítio jusbrasil.com.br, acesso em 07/04/2017.
} 
desde a morte da genitora mantendo, no registro, os dados da mãe biológica. Segundo consta dos autos, a menina evidenciou tal desejo, o que foi acatado pelo magistrado ${ }^{14}$.

Segundo análise das decisões existentes, parece que o rumo que está sendo tomado é no sentido de não romper os laços biológicos, quando não haja motivos para a destituição do poder familiar, - casos em que a mãe entrega a criança por ausência de condições financeiras ou em caso de falecimento, por exemplo - permitindo, ao acolher o pedido de adoção, o registro simultâneo de vínculos.

Nenhum julgado foi encontrado permitindo a simultaneidade quando, anteriormente, tenha havido uma adoção, com a determinação do rompimento dos laços biológicos. Como será enfrentada a questão é a grande interrogação.

Se for negado, ao filho adotivo, o direito de restabelecer os laços biológicos destituídos anteriormente, por decisão judicial, mormente se, na prática, esses vínculos sejam mantidos ou restaurados, no futuro, passa-se a ter um tratamento não isonômico de filiação, ferindo os preceitos constitucionais, impossibilitadores de qualquer forma de discriminação.

Por outro lado, se for aceito, se terá uma decisão judicial que rompe os vínculos biológicos e, posteriormente, uma nova decisão judicial, que restabelece estes mesmos vínculos, criando uma situação de reversibilidade de destituição de poder familiar, não autorizada legalmente.

Sabe-se que a adoção se trata de medida excepcional, e, em regra, requer a destituição do poder familiar, com a retirada da criança da sua família de origem, para que seja colocada sob a responsabilidade de nova família. Se no passado, não se poderia cogitar na manutenção dos vínculos biológicos, garantindo a lei, posteriormente, o direito ao reconhecimento da origem para fins genéticos apenas, hoje o desafio é ainda maior.

\footnotetext{
14 Notícia extraída na página do Poder Judiciário do Ceará, sítio www.tjce.jus.br;
} 
Seria a hora de se repensar a própria adoção, para que os vínculos biológicos não sejam desfeitos de imediato e a criança possa, no futuro, ao atingir a maioridade, acatar ou não o duplo vínculo? Ou melhor seria estabelecer critérios para o acolhimento da multiparentalidade, tipificando as situações em que se pode ou não acolher a simultaneidade de vínculos? Estas e outras questões precisam ser ponderadas, diante do novo e instigante tema da multiparentalidade.

\section{CONCLUSÃO}

A CRFB/88 estabeleceu um novo marco teórico no Direito de Família brasileiro, colocando o homem como o centro das preocupações normativas. Deixou para trás o ranço previsto no Código Civil de 1916, que reconhecia a família casamentária como único modelo instituinte de entidade familiar, deixando marginalizadas todas as demais formas de união já existentes, desde o Brasil colonial.

A sociedade, assim como a família e a filiação, encontram-se em uma fase de travessia, de constantes mudanças, em busca de novas fronteiras, de novos contornos que, longe de serem estáticos, revelam-se em constante mutação.

Diante de novas formas de convivência, da reconstrução da entidade familiar e da pluralidade de relações, a convivência dos filhos com os companheiros da mãe ou do pai tornou-se cenário comum. Conflitos de paternidade passaram a se tornar recorrentes nas pautas do Poder Judiciário, em busca de soluções nem sempre fáceis e, normalmente, sem soluções legais previstas.

Hierarquia deveria ser estabelecida? No primeiro momento se acreditou que sim, já que não se vislumbrava possibilidade de reconhecimento simultâneo. Mas em pouco tempo a questão chegou ao STF, que não se limitou a estabelecer a prepondância de um vínculo sobre 
o outro, pelo contrário, entendeu ser cabível a multiparentalidade, com o reconhecimento de todos os efeitos legais.

Diante deste contexto, surge a nova teoria como uma solução apta a reconhecer parentalidades com moldes diversos, consolidadas pelo sangue ou pelo afeto, de forma simultânea, já que ambas se caracterizam em vínculos que, apesar de transcenderem as normas, revelam-se como verdades concretas e efetivas.

A partir de agora, a multiparentalidde passa a não só ser possível para fins registrais, como garante todos os direitos e deveres inerentes aos vínculos parentais. Ao mesmo tempo em que pode ser entendida como um avanço na área do Direito de Família, em atendimento ao reconhecimento de situações fáticas, também é certo que o tema precisa de ponderação e especial atenção, até porque, o Brasil está a tomar um rumo diferente dos demais Países.

Variadas indagações surgem em torno da questão, dado o tema ser recente e representar uma verdadeira quebra de paradigmas, até então existente. Perguntas como se a simultaneidade de vínculos será encarada como regra ou como situação excepcional no que tange à filiação, ainda se encontra sem resposta definitiva.

Acredita-se que avaliar o caso e buscar uma alternativa que melhor se aproxime do mundo real, verificando se o estabelecimento de vínculos é recíproco e a convivência com ambos os pais ou com ambas as mães, de fato ocorre, será salutar para o deslinde concreto.

Quando o pai biológico é quem consta no registro, parece evidente a necessária demonstração da construção dos laços afetivos, para que seja possível a inclusão também do pai socioafetivo; Porém, quando no registro consta o pai socioafetivo, e se quer inserir o biológico, pela construção do STF, não é obrigatória a comprovação ou existência de convivência, bastando a prova dos laços genéticos. Isso cria uma distinção entre a figura de pai e de genitor, e embora não enfrentada a questão que, inclusive, foi objeto do voto divergente do Ministro Luiz Edson Fachin, também desafia a construção de resposta. 
No mais, dando ênfase ao questionamento central desta investigação, verificou-se que nos casos de adoção à brasileira, há uma tendência à aceitação da multiparentalidade, sem muitas restrições. Com relação à adoção regular, duas situações distintas surgiram, envolvendo casos que contemplavam a necessidade ou não de destituição do poder familiar.

Na primeira situação, em que não havia razão para destituição do poder familiar, com base nos julgados encontrados, embora ainda tímidas as decisões sobre multiparentalidade, o acolhimento do registro simultâneo, não pareceu ser um problema, pelo contrário. Em prol do melhor interesse da criança, ignorou-se o rompimento dos vínculos biológicos, mantendo-se no registro as relações familiais simultâneas;

No segundo caso, no que tange à adoção com destituição do poder familiar, a questão se complica. Embora não se tenha encontrado julgados nesse sentido, pelas razões expostas nas decisões em que não houve rompimento dos vínculos biológicos, a lógica parece remeter a uma situação não autorizada de multiparentalidade, até porque fere disposição expressa legal, prevista no Estatuto da Criança e do Adolescente.

A questão é espinhosa e merece maiores reflexões. Como será tratado o tema daqui para a frente é a grande indagação, mas certamente exigirá muita sensibilidade dos julgadores, que se defrontarão com um dilema que encontra, de um lado, a reversibilidade não autorizada da destituição do poder familiar e, de outro, uma afronta ao princípio da isonomia, previsto constitucionalmente.

\section{REFERÊNCIAS}


ALMEIDA, Ranata Barbosa de; RODRIGUES JÚNIOR. Walsir Edson. Direito Civil: Família. Rio de Janeiro: Lumen Juris, 2010.

BAUMAN, Zigmunt. Amor Líquido: sobre as fragilidade dos laços humanos. Tradução de Carlos Alberto Medeiros. Rio de Janeiro: Zahar, 2004.

CASSETARI, Cristiano. Multiparentalidade e parentalidade socioafetiva. São Paulo: Atlas, 2014.

DIAS, Maria Berenice. Manual de Direito das Famílias. 9 ed. rev. atual. e ampl. São Paulo: Editora Revista dos Tribunais, 2013.

FARIAS, Cristiano Chaves de; ROSENVALD. Nelson. Curso de Direito Civil: Famílias. 9 ed. Salvador: Jus Podivm, 2017.

GHILARDI, Dóris. A possibilidade de reconhecimento da multiparentalidade: vínculo biológico x vínculo afetivo, uma análise a partir do julgado da AC n. 2011.027498-4 do TJSC, in Revista Brasileira de Direito das Famílias e das Sucessões - n. 36, Porto Alegre:Magister/IBDFAM, out./nov. 2013.

MADALENO, Rolf. Filhos Adotados em confronto com os filhos destoados do Recurso Extraordinário 898.060 do STF. Revista IBDFAM - n. 29, Belo Horizonte: out/nov de 2016/ Multiparentalidade, encarte especial, IBDFAM, 2017.

PEREIRA, Rodrigo da Cunha. Direito de Família: uma abordagem psicanalítica. 4 ed. Rio de Janeiro: Forense, 2012.

WELTER, Belmiro Pedro. Teoria Tridimensional do Direito de Família. Porto Alegre: Livraria do Advogado, 2009. 